\title{
Removal of Azo Dyes From Aqueous Solution Using Fenton and Modified Fenton Processes
}

\author{
Hossein Jafari Mansoorian ${ }^{1,}$; Edris Bazrafshan ${ }^{1}$; Ahmadreza Yari ${ }^{2}$; Mostafa Alizadeh ${ }^{3}$ \\ ${ }_{1}^{1}$ Health Promotion Research Center, Zahedan University of Medical Sciences, Zahedan, IR Iran \\ ${ }^{2}$ Department of Environmental Health, School of Public Health, Qom University of Medical Sciences, Qom, IR Iran \\ ${ }^{3}$ Students Scientific Research Center, Zahedan University of Medical Sciences, Zahedan, IR Iran \\ ${ }^{*}$ Corresponding author: Hossein Jafari Mansoorian, Health Promotion Research Center, Zahedan University of Medical Sciences, Zahedan, IR Iran. Tel: +98-918813385, Fax: +98- \\ 5413425837, E-mail: h.mansoorian@yahoo.com
}

Received: October 21, 2013; Revised: December 16, 2013; Accepted: December 21, 2013

\begin{abstract}
Background: Fenton $\left(\mathrm{Fe}^{2+}\right.$ and $\left.\mathrm{H}_{2} \mathrm{O}_{2}\right)$ and modified Fenton $\left(\mathrm{Fe}^{3+}\right.$ and $\left.\mathrm{H}_{2} \mathrm{O}_{2}\right)$ are two popular methods used in advanced oxidation processes (AOP) and degradation of persistent organic pollutants (POPs), such as dye compounds. In these processes, $\mathrm{Fe}^{2+}$ and $\mathrm{Fe}^{3+}$ as catalysts and $\mathrm{H}_{2} \mathrm{O}_{2}$ as the oxidizing agent are added to the reactor.

Objectives: The aim of the current study is to assess the abovementioned methods for removal of Reactive Red 198 and Blue Reactive 19 from aqueous solutions.

Materials and Methods: This research was carried out using lab-scale. After preparation of RB-19 and RR-198 stock solutions (1000 ppm), optimum $\mathrm{pH}$ and temperature were determined within the range of $(3-11)$ and $\left(15^{\circ} \mathrm{C}-40^{\circ} \mathrm{C}\right)$ respectively, and specific amounts of $\mathrm{Fe}^{2+}$ and $\mathrm{Fe}^{3+}(0.8,1,3,7,14$ and $32 \mathrm{mM})$ were prepared by adding $\mathrm{FeSo}_{4}$. $7 \mathrm{H}_{2} \mathrm{O}$ and $\mathrm{FeCl}_{3}$, and $\mathrm{H}_{2} \mathrm{O}_{2} 30 \% \mathrm{~W} / \mathrm{W}(2,5,11,23,47$ and $94 \mathrm{mM})$ were added to the solutions to establish the $\mathrm{H}_{2} \mathrm{O}_{2} / \mathrm{Fe}^{2+}, \mathrm{Fe}^{3+}$ molar ratios. Standard jar tests were conducted using jar test apparatus. After sedimentation time, samples were filtered through a $0.45 \mu \mathrm{m}$ fiber membrane, and then final dye concentrations were measured using a UV/VIS spectrophotometer.

Results: The highest dye removal efficiency in both Fenton and modified Fenton methods were obtained at the optimum pH =3, optimum reaction time of 10 minutes, optimum temperature at $25^{\circ} \mathrm{C}$ and $\mathrm{H}_{2} \mathrm{O}_{2} / \mathrm{Fe}^{2+}$ and $\mathrm{H}_{2} \mathrm{O}_{2} / \mathrm{Fe}^{3+}$ concentrations of 11.3 and $5.1 \mathrm{mM}$, respectively. In the Fenton reaction the maximum efficiency was obtained at $94.70 \%$ and $99.31 \%$ for reactive red 198 and reactive blue 19, respectively. Moreover, by the modified Fenton method the maximum removal efficiency for reactive red 198 and reactive blue 19 was $94.8 \%$ and $99.43 \%$. Conclusions: Fenton and modified Fenton processes could be used as very effective methods for removal of reactive red 198 and blue reactive 19 from aqueous solutions.
\end{abstract}

Keywords: Fenton's reagent; reactive red 198; Adsorption; Waste Water

\section{Background}

Textile and dyeing industrial are considered as the major sources of water consumption. According to the production rate, water consumption varies between 25 - $250 \mathrm{~m}^{3} /$ ton of product. The resulting wastewater contains BOD, COD and synthetic dyes $(1,2)$, and discharge of contaminated effluent without any treatment into the environment creates depressed photosynthesis and aquatic plant demise which characteristics are considered as environmental threats (3). Dyes are substances with complex structures which contain atoms: electron acceptors such as chromophore or electron donors such as ecsocrimium, which determine its strength and solubility in water $(4,5)$. Based on the application, dyes are categorized as Watt, reactive, direct, cation, acidic and disperse, of which Azo dyes are found in more than 50\% of dyes $(6,7)$. Azo reactive dyes are anionic and soluble in water. Because of their variety of colors, easy utilization, good stability during washing and low energy consumption, Azo dyes are applied more frequently in the textile industry $(5,8)$. These dyes have strong resistance to photolysis and chemical decomposition, and in some cases there are special components in their structures that have carcinogenic and mutagenic consequences (5, 9). Even the presence of a small quantity of dye (less than $1 \mathrm{ppm}$ ) in water has adverse effects. Synthetic dyes are used in abundance by textile (60\%), paper making (10\%) and plastics industries. Now, over 10000 varied types of commercial pigments and dyes are produced annually, about $7 \times 10^{5}$ tons (10). Their absorption into biological masses are very weak and there is no decomposition in aerobic conditions. Reactive red 198 and blue reactive 19 are mono Azos which are used in textile plants in Iran industrial managers. 
$(3,11,12)$. Different technologies are applied to decrease absorption of these dyes into the environment such as ion exchange, chemical sedimentation, electrochemical reduction, advanced oxidation, membrane process and absorption (13-15).

The limitations of the available technologies include dense solution disposal, high energy consumption, high operation costs, excessive production of sludge, expensive facilities (16-18). Therefore, finding new and effective alternatives is necessary to remove contaminants from aquatic environments. One effective technique is advanced oxidation which can be used to remove toxic and resistant chemicals and reprocess them into mineral form to release carbon dioxide and oxygen. Advanced chemical oxidation processes such as chemical, photochemical, photocatalytic methods and electrochemical methods $\left(\mathrm{UV} / \mathrm{O}_{3}, \mathrm{UV} / \mathrm{H}_{2} \mathrm{O}_{2}\right.$, Fenton, modified Fenton, and ultrasound) are decrepitating and produce hydroxyl radicals. In this process, hydroxyl radicals using Fe(II) and $\mathrm{Fe}(\mathrm{III})$ catalysts are generated easily as follows (19-21):

Fenton reactions:

$$
\begin{aligned}
& \text { 1. } \mathrm{Fe}^{2+}+\mathrm{H}_{2} \mathrm{O}_{2} \rightarrow \mathrm{Fe}^{3+}+\mathrm{OH}^{\bullet}+\mathrm{OH}^{-} \\
& \text {2. } \mathrm{Fe}^{3+}+\mathrm{H}_{2} \mathrm{O}_{2} \rightarrow \mathrm{Fe}^{-} \mathrm{OOH}^{2+}+\mathrm{H}^{+} \\
& \text {3. } \mathrm{Fe}^{-} \mathrm{OOH}^{2+} \rightarrow \mathrm{Fe}^{3+}+\mathrm{O}_{2} \mathrm{H}^{\bullet} \\
& \text { 4. } \mathrm{Fe}^{3+}+\mathrm{O}_{2} \mathrm{H}^{\bullet} \rightarrow \mathrm{Fe}^{2+}+\mathrm{O}_{2}+\mathrm{H}^{+} \\
& \text {5. } \mathrm{Fe}^{2+}+\mathrm{OH}^{\bullet} \rightarrow \mathrm{Fe}^{3+}+\mathrm{OH}^{-} \\
& \text {6. } \mathrm{H}_{2} \mathrm{O}_{2}+\mathrm{OH}^{\bullet} \rightarrow \mathrm{H}_{2} \mathrm{O}+\mathrm{O}_{2} \mathrm{H}^{\bullet} \\
& \text { 7. } \mathrm{OH}^{\bullet}+\text { Reactive dye production }
\end{aligned}
$$

Reactions related to modified Fenton process:

1. $\mathrm{Fe}^{3+}+\mathrm{H}_{2} \mathrm{O}_{2} \rightarrow \mathrm{Fe}^{2+}+\mathrm{HO}_{2} \cdot+\mathrm{H}^{+}$

2. $\mathrm{HO}_{2} \cdot \rightarrow \mathrm{O}_{2} \cdot-+\mathrm{H}^{+}$

3. $\mathrm{HO}_{2}+\mathrm{Fe}^{3+} \rightarrow \mathrm{Fe}^{2+}+\mathrm{O}_{2}+\mathrm{H}^{+}$

Efficiency of the advanced oxidation process is ds on the oxidation rate of hydroxyl radical. These radicals have high reaction rates, oxidation potential, low selectivity for organic components and will destroy contaminants in four ways: (i) addition of $\mathrm{OH}^{-}$to structure of contaminant (ii) hydrogen absorption (iii) electron transmission (iv) reaction between free radicals that can lead to the formation of stable compounds. Among the various processes of advanced oxidation, using the Fenton $\left(\mathrm{H}_{2} \mathrm{O}_{2}\right)$ $\left.\mathrm{Fe}^{2+}\right)$ and modified Fenton $\left(\mathrm{H}_{2} \mathrm{O}_{2} / \mathrm{Fe}^{3+}\right)$ methods have greater advantages, such as simple operation, low reaction time, using of coagulation and flocculation processes, non-toxic compound production, economic viability, and possibility of utilization at different scales. Disadvantages include costly treatment processes and disposal of sludge, ferrous ions are consumed faster than produced, the process is limited to low $\mathrm{pH}$ range, and deactivation of iron ions due to bonding of iron ions with various reagents such as anion phosphate, oxidation of the product as well as further water pollution due to existence of catalysts such as iron salt. The main steps involved in the Fenton process are (i) oxidation, (ii) neutralization, (iii) flocculation and (iv) sedimentation (22-24). Research shows that modified Fenton is very effective in treating colored wastewater but so far little research has been done using this method.

\section{Objectives}

This paper presents a brief review on the role of Fenton and modified Fenton reactions in the removal of contaminants (blue reactive 19 and reactive red 198) from aqueous solutions.

\section{Materials and Methods}

Reactive dyes were bought from Alvan Sabet Company (Iran); other chemical material was obtained from Merck Company (Germany). The chemical structures and a number of the physicochemical properties of the dyes used are listed in Table 1.

This research was carried out using lab-scale in chemistry laboratory of Zahedan University of Medical Sciences. The advanced oxidation experiments were started in a Plexiglas reactor $(1 \mathrm{~L})$ as batch system. Ranges of experimental parameters are given in Table 2. After preparation of RB-19, RR-198 Stock solutions (1000 ppm), working solutions were made by dissolving stock solution in deionized water. After determination of optimum $\mathrm{pH}$ within range of (3-11) and temperature $\left(15^{\circ} \mathrm{C}-40^{\circ} \mathrm{C}\right)$, specific amounts of $\mathrm{Fe}^{2+}$ and $\mathrm{Fe}^{3+}(0.8,1,3,7,14$ and $32 \mathrm{mM})$ were prepared by adding $\mathrm{FeSo}_{4} \cdot 7 \mathrm{H} 2 \mathrm{O}$ and $\mathrm{FeCl}_{3}$, and determined amounts of $\mathrm{H}_{2} \mathrm{O}_{2} 30 \% \mathrm{~W} / \mathrm{W}(2,5,11,23,47$ and 94 $\mathrm{mM}$ ) were added to the solution to create the $\mathrm{H}_{2} \mathrm{O}_{2} / \mathrm{Fe}^{2+}$ and $\mathrm{H}_{2} \mathrm{O}_{2} / \mathrm{Fe}^{3+}$ molar ratios. Standard Jar Tests were conducted using jar test apparatus (model OSK8996). After sedimentation time, supernatant samples were collected from the solution using a $50 \mathrm{~mL}$ pipet. Collected samples were filtered through a $0.45 \mu \mathrm{m}$ fiber membrane, then final dye concentrations were measured using a UV/VIS spectrophotometer (optima SP-3000 plus) at $590 \mathrm{~nm}$ for RB-19 and $518 \mathrm{~nm}$ for RR-198. The dye removal percentage ( $\mathrm{R} \%$ ) was calculated as follows (Equation 1):

Equation 1. $\quad R(\%)=\frac{C_{0}-C}{C_{0}} \times 100$

Where $\mathrm{C}_{0}$ is the initial concentration $(\mathrm{mg} / \mathrm{L})$ and $\mathrm{C}$ is the final dye concentration $(\mathrm{mg} / \mathrm{L})$.

\section{Results}

It has been established that $\mathrm{pH}$ has a significant influence on the performance of oxidation processes. In the present study the effect of $\mathrm{pH}$ (3-11) on removal of two dyes, reactive red 198 (RR198) and blue reactive 19 (RB 19), were investigated. Figure 1 shows that the highest removal efficiency for the dyes studied occurred at $\mathrm{pH} 3$ for both processes, modified Fenton and Fenton. Final values of $\mathrm{pH}$ samples at the end of the experiments are presented in Figure 2. 
Optimum reaction time for Fenton and modified Fenton methods depends on the initial concentration and variance of catalyst dosage. Dye removal efficiency was investigated at fixed $\mathrm{pH}$ and $\mathrm{H}_{2} \mathrm{O}_{2} / \mathrm{Fe}^{2+}, \mathrm{Fe}^{3+}$ ratio conditions. As it can be seen in Figure 3, optimum reaction time for both processes was obtained at 10 minutes.

Temperature has a positive effect on treatment efficiency; hence, six temperatures were investigated in this study. As shown in Figure 4, the best removal efficiency for both methods was obtained at $25^{\circ} \mathrm{C}$. In addition, this effect was studied in various molar ratios. Maximum dye removal in optimum molar ratios in Fenton and modified Fenton methods were obtained at $\mathrm{H}_{2} \mathrm{O}_{2} / \mathrm{Fe}^{2+}=$ 11.3 and $\mathrm{H}_{2} \mathrm{O}_{2} / \mathrm{Fe}^{3+}=5.1$, respectively (Figures 5 to 8 ). To determine the effect of dye concentration on removal efficiency, mentioned dyes were examined at three concentrations (10, 50 and $500 \mathrm{mg} / \mathrm{L})$. Figures 5 to 8 reveal dye removal efficiency in various concentrations. As can be seen, removal efficiency was increased by increasing dye concentration.

\begin{tabular}{|l|l|l|}
\hline \hline Characteristics & Reactive Red 198 \\
\hline $\begin{array}{l}\text { Chemical } \\
\text { structure }\end{array}$ & Reactive Blue 19 \\
\hline $\begin{array}{l}\text { Molecular } \\
\text { formula }\end{array}$ & $\mathrm{C}_{27} \mathrm{H}_{18} \mathrm{C}_{1} \mathrm{~N}_{7} \mathrm{Na}_{4} \mathrm{O}_{15} \mathrm{~S}_{5}$ \\
\hline $\begin{array}{l}\text { Molecular } \\
\text { weight, g/mol }\end{array}$ & 967.5 & 626.5 \\
\hline$\lambda$ max, nm & 520 & 592 \\
\hline
\end{tabular}

Table 1. Characteristics of Dyes Used

Table 2. Ranges of Experimental Parameters ${ }^{\mathrm{a}}$

\begin{tabular}{|c|c|}
\hline Parameters & Ranges of Experimental \\
\hline \multicolumn{2}{|l|}{ Mixing speeds, rpm } \\
\hline $1 \mathrm{~min}$ & 80 \\
\hline $80 \mathrm{~min}$ & 30 \\
\hline Temperatures, ${ }^{\circ} \mathrm{C}$ & $15,20,25,30,35,40$ \\
\hline Sampling Times, min & $10,20,40,80$ \\
\hline Initial dyes concentrations, $\mathrm{Mg} / \mathrm{L}$ & $10,50,500$ \\
\hline $\mathrm{H}_{2} \mathrm{O}_{2}$ concentrations, $\mathrm{mM}$ & $2,5,11,23,47,94$ \\
\hline $\mathrm{Fe}^{3+}, \mathrm{Fe}^{2+}$ concentrations, $\mathrm{mM}$ & $0.8,1,3,7,14,32$ \\
\hline pH & $3,5,7,9,11$ \\
\hline
\end{tabular}

abbreviation; rpm, revolutions per minute.

Figure 1. Effect of pH on Reactive Red 198 and RB-19 Removal Percentage in Fenton and Modified Fenton Methods

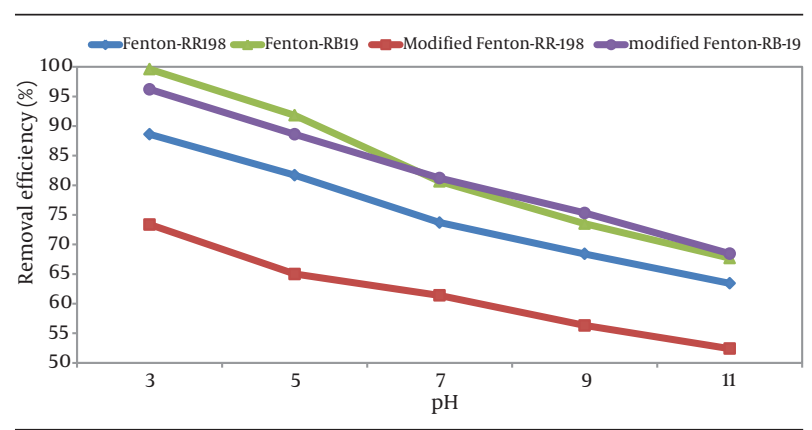

Temperatures $25^{\circ} \mathrm{C}$, reaction time of 20 minutes, dyes concentrations 50 $\mathrm{mg} / \mathrm{L}, \mathrm{H}_{2} \mathrm{O}_{2} / \mathrm{Fe}^{2+}, \mathrm{Fe}^{3+}=11.3$.
Figure 2. Final $\mathrm{pH}$ in Dye Removal in Different Concentration of $\mathrm{H}_{2} \mathrm{O}_{2} /$ $\mathrm{Fe}^{2+}$ and $\mathrm{H}_{2} \mathrm{O}_{2} / \mathrm{Fe}^{3+}$ in Fenton and Modified Fenton Methods

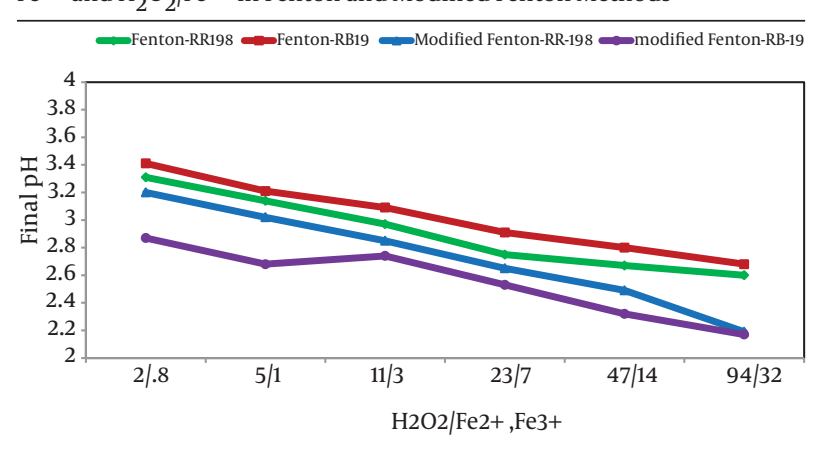

Initial $\mathrm{pH}=3$. 
Jafari Mansoorian Het al.

Figure 3. Effect of Contact Time on Reactive Red 198 and Reactive Blue 19 Removal Percentage in Fenton and Modified Fenton Methods

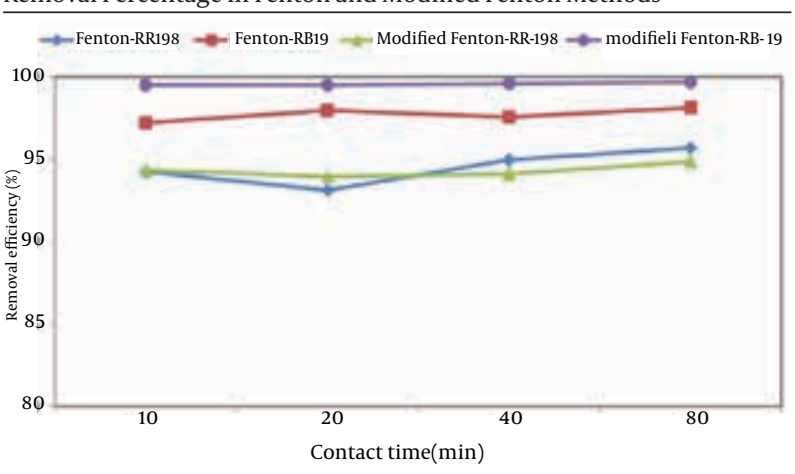

Temperatures $25^{\circ} \mathrm{C}, \mathrm{pH}=3$, dye concentration $50 \mathrm{mg} / \mathrm{L}, \mathrm{H}_{2} \mathrm{O}_{2} / \mathrm{Fe}^{2+}, \mathrm{Fe}^{3+}$ $=11.3$.
Figure 4. Effect of Temperature on Reactive Red 198 and Reactive Blue 19 Removal Percentage in Fenton and Modified Fenton Methods

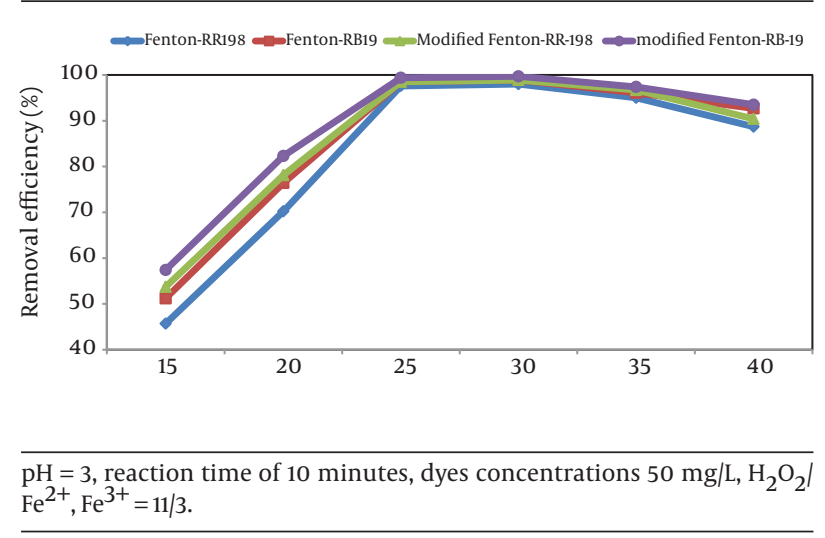

Figure 5. Removal Percentage and Residue Concentration of reactive red 198 in Different Dye Concentrations and Molar Ratios of $\mathrm{H}_{2} \mathrm{O}_{2} / \mathrm{Fe}^{2+}$ in Fenton Method

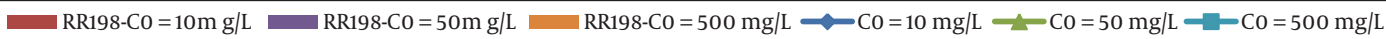

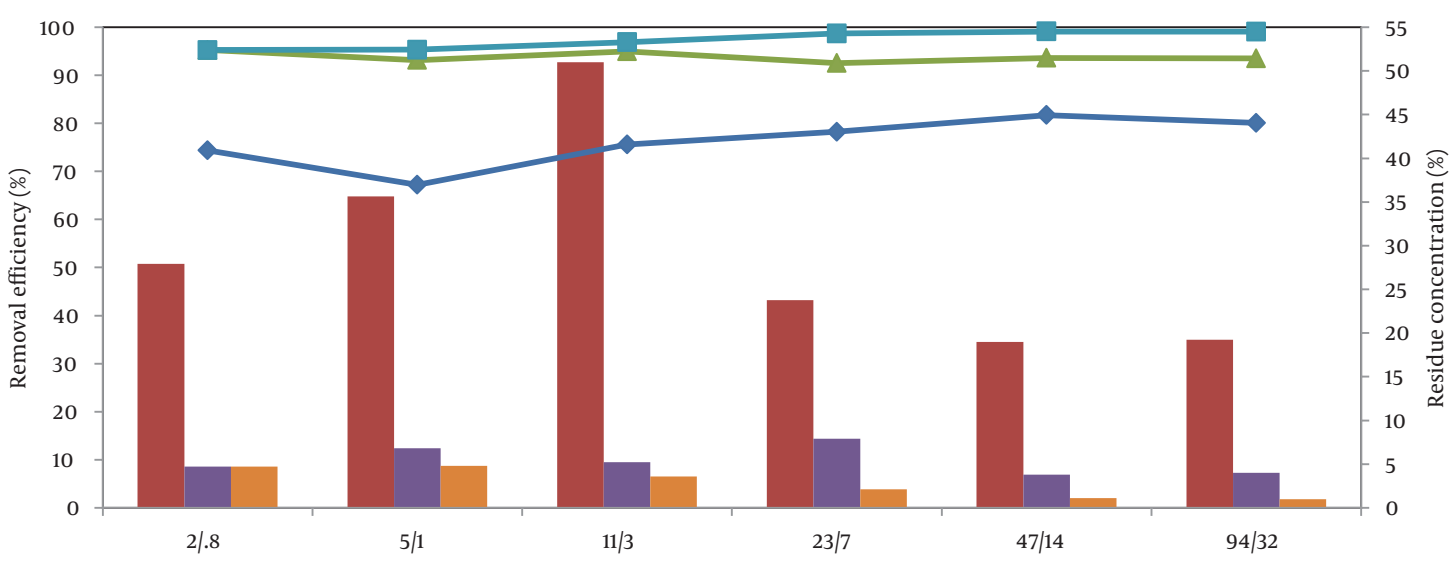

Temperatures $25^{\circ} \mathrm{C}, \mathrm{pH}=3$, reaction time of 10 minutes.

Figure 6. Removal Percentage and Residue Concentration of Reactive Blue 19 in Different Dye Concentrations and Molar Ratios of $\mathrm{H}_{2} \mathrm{O}_{2} / \mathrm{Fe}^{2+}$ in Fenton method

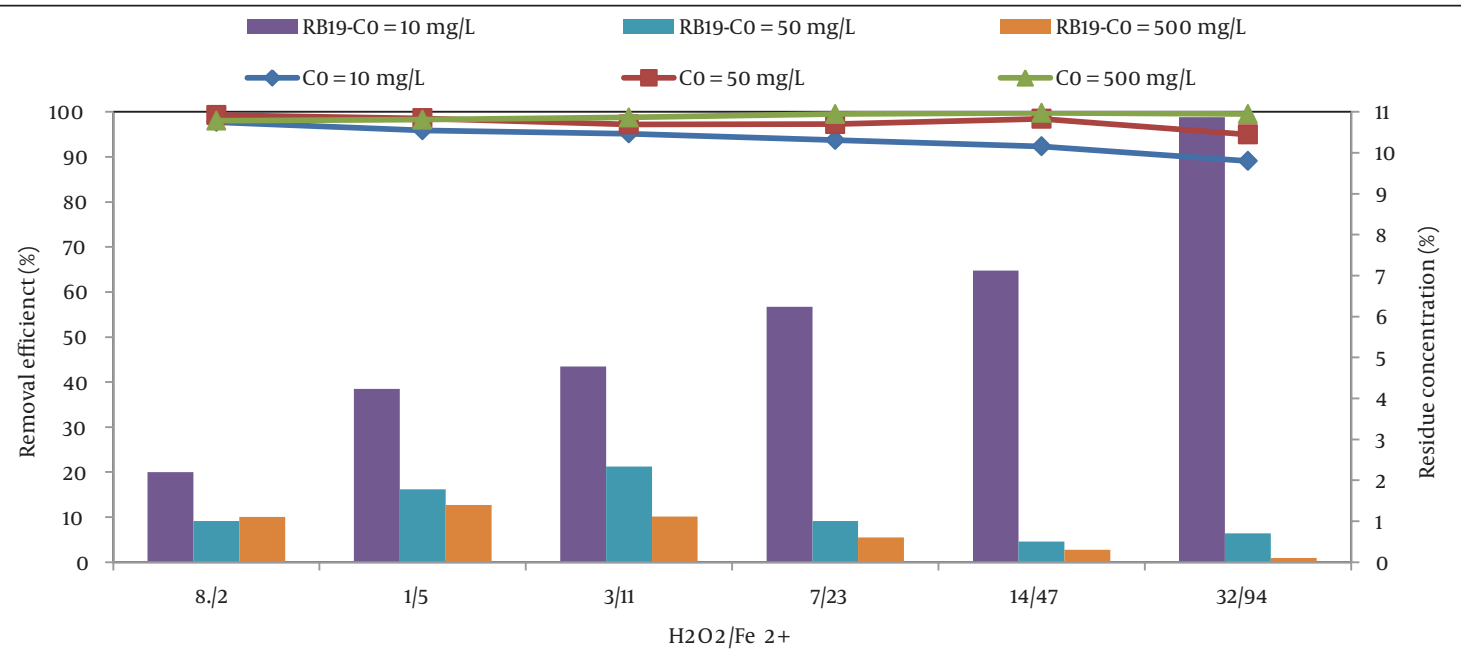

Temperatures $25^{\circ} \mathrm{C}, \mathrm{pH}=3$, reaction time of 10 minutes. 
Figure 7. Removal Percentage and Residue Concentration of Reactive Red 198 in Different Dye Concentrations and Molar Ratios of $\mathrm{H}_{2} \mathrm{O}_{2} / \mathrm{Fe}^{3+}$ in Modified Fenton Method

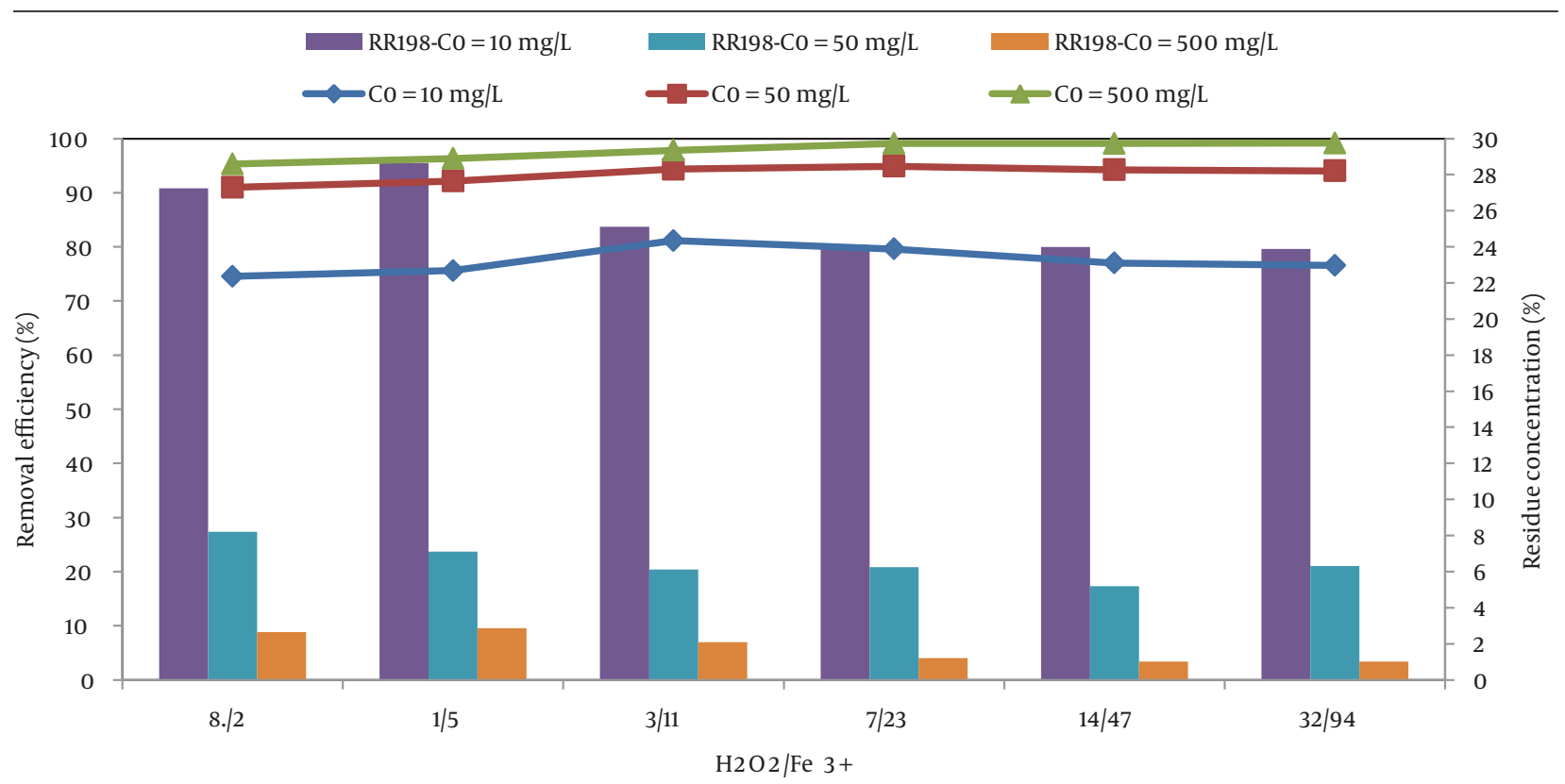

Temperatures $25^{\circ} \mathrm{C}, \mathrm{pH}=3$, reaction time of 10 minutes.

Figure 8. Removal \% and Residue Concentration of Reactive Blue 19 in Different Dye Concentrations and Molar Ratios of $\mathrm{H}_{2} \mathrm{O}_{2} / \mathrm{Fe}^{3+}$ in Modified Fenton Method

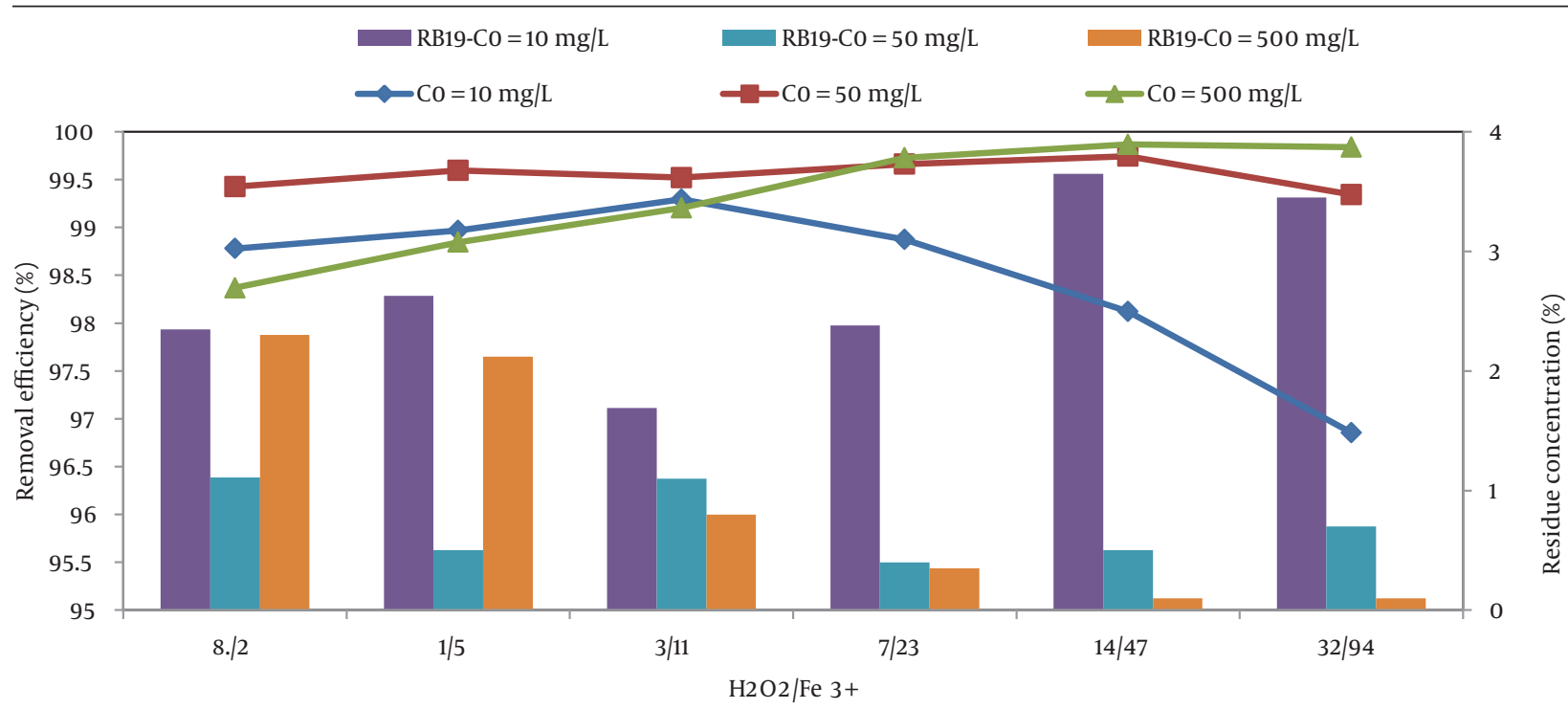

Temperatures $25^{\circ} \mathrm{C}, \mathrm{pH}=3$, reaction time of 10 minutes. 


\section{Discussion}

The present study has evaluated a number of parameters such as $\mathrm{pH}$, contact time, temperature, initial hydrogen peroxide $\mathrm{H}_{2} \mathrm{O}_{2}$ concentration and iron (II), iron (III) concentrations.

\subsection{Effect of $\mathrm{pH}$}

$\mathrm{pH}$ is one of the effective parameter on dye removal efficiency in Fenton and modified Fenton processes. $\mathrm{pH}$ plays an important role in production of radicals that are effective in increase of oxidation efficiency. It has been proven that the Fenton reactions in acidic $\mathrm{pH}$ are more effective than neutral $\mathrm{pH}$ (25); On the other hand, oxidation reactions are slower in neutral $\mathrm{pH}$ due to hydroxylation of iron (26). Figures 1 and 2 show that the maximum removal percentage reached is $95 \%$ in $\mathrm{pH}=3$, thus the optimum $\mathrm{pH}$ was obtained as 3 for all of samples. In $\mathrm{pH}$ $>3$, because of Fe(III) sedimentation, Fenton efficiency decreases, the synthetic hydroxide produced can hydrolyze the available hydrogen peroxide to other products $\left(\mathrm{O}_{2}\right.$ and $\left.\mathrm{H}_{2} \mathrm{O}\right)$ that subsequently cause oxidation and hydroxyl ions decline. Moreover in $\mathrm{pH}>3$, the $\mathrm{Fe}(\mathrm{II})$ [Fe(II) $\left.\left(\mathrm{H}_{2} \mathrm{O}\right)_{6}\right]^{2+}$ substance can react with hydrogen peroxide peroxide better than the $\mathrm{Fe}(\mathrm{II})\left[\mathrm{Fe}(\mathrm{II})(\mathrm{OH})\left(\mathrm{H}_{2} \mathrm{O}\right)_{5}{ }^{2+}\right]$ substance $(27,28)$. In lower $\mathrm{pH}$, the additionally droxide ions react in reverse which leads to further Fe(III) production. As shown in Figure 8 below (27).

8. $\mathrm{Fe}^{3+}+\mathrm{H}_{2} \mathrm{O}_{2} \rightarrow \mathrm{Fe}-\mathrm{OOH}^{2+}+\mathrm{H}^{+}$

As shown above, the generation of $\mathrm{Fe}(\mathrm{III})$ to $\mathrm{Fe}(\mathrm{II})$ is prohibited and as a result the available Fe(II) concentration producing hydroxyl radical was declined. These results are in accordance with other reported research (29). In the Fenton method, iron ions will become sediment in higher $\mathrm{pH}$ in the form of ferric hydroxide. In low $\mathrm{pH}$ iron ions can form a stable substance with hydrogen peroxide leading to the inactivation of the catalyst and subsequently removal efficiency decreases. Acidic solutions have a propensity to produce hydrogen peroxide (Equation 9), but according to equation 10, in low $\mathrm{pH}$, the number of active sites for hydrogen peroxide is declined. In $\mathrm{pH}<3$ hydrogen peroxide forms ecsoniumion and remains constant. According to other research, $\mathrm{pH}=$ 3 because of renewed production of Fe(II) via reaction between $\mathrm{Fe}(\mathrm{III})$ and hydrogen peroxide, the Fenton process has less effect $(10,22,23)$.

$$
\begin{aligned}
& \text { 9. } \mathrm{O}_{2}+2 \mathrm{H}^{+}+2^{\mathrm{e}-} \rightarrow \mathrm{H}_{2} \mathrm{O}_{2} \\
& \text { 10. } \mathrm{H}_{2} \mathrm{O}_{2}+2 \mathrm{H}^{+}+2^{\mathrm{e}-} \rightarrow 2 \mathrm{H}_{2} \mathrm{O} \\
& \text { 11. } \mathrm{H}_{2} \mathrm{O}_{2}+\mathrm{H}^{+} \rightarrow \mathrm{H}_{3} \mathrm{O}_{2}^{+}
\end{aligned}
$$

Figure 5 shows the final pH of the solution and it can be concluded that by increasing the iron concentration, the $\mathrm{pH}$ decreases from 4 to 2.5 ; this may be due to the hydrolysis of water and production of further $\mathrm{H}^{+}$ions (28). Yuang et al. obtained optimum $\mathrm{pH}=2-4$ for treatment of pharmacy wastewater; also the optimum $\mathrm{pH}$ for dye removal was 3 - $4(30,31)$.

\subsection{The Effect of Contact Time}

To study the optimum time and its effect in the Fenton and modified Fenton processes, experiments were performed for 10 to 80 minutes to determine optimum time of the Fenton and modified Fenton efficiency in dye removal. As shown in Figure 3, maximum efficiency was attained at 10 minutes for both of the processes which was more than $94 \%$. It is clear that removal efficiency increase was linear and slow thereafter. Linear increase of dye removal efficiency can be related to chemical oxidation of dye by $\mathrm{OH}$. In advanced chemical oxidation, with methods other than the Fenton process, $\mathrm{OH}$ production in the environment is continuous, but in the Fenton process high concentrations of $\mathrm{OH}$ are producedin the first minutes of the process (29). Fenton oxidation of organic compounds showed that in the early stages the initial rate of mineralization was fast with Fenton reagents, due to the immediate formation of hydroxyl radicals, where the color could obviously be reduced. It demonstrated that the recalcitrant organic compounds which were in the wastewater had been oxidized by $\mathrm{HO}^{\bullet}$ after reaction time of 60 minutes, resulted in the curve slightly ascending (21). In the Fenton oxidation system, the hydroxyl radicals made, which had extremely high oxidizing ability, could oxidize into hardness with the decomposition of organic compounds in a short time. Also after the rapid and slow mixing, large amounts of pinpoint flocs were consistently observed and took a very long time to settle down. These tiny amounts of floc frequently interfered with color and measurement. The majority of color was generally removed after rather short oxidation times: one minute (26), 10 minutes (18), and 15 minutes (27).

\subsection{The Effect of Temperature}

Although temperature has a positive effect on treatment efficiency in the Fenton process, it has a less effect than other factors. Very low or high temperature has adverse results on the efficiency process (28). Figure 5 shows the highest removal efficiency at $25^{\circ} \mathrm{C}$. Goi et al. (32) reported that $30^{\circ} \mathrm{C}$ is as an optimum temperature for decomposition of silicicacid. Also it has been proven that temperatures between $20^{\circ} \mathrm{C}-30^{\circ} \mathrm{C}$ can be used as the best temperature because of high efficiency (32). Zhang et al. concluded that COD removal efficiency was increased gradually by varying temperature from $15^{\circ} \mathrm{C}-35^{\circ} \mathrm{C}(28)$. Weng et al. reported that dye decomposition rate was less at lower temperatures (33). The optimum temperature was estimated to be $45^{\circ} \mathrm{C}$ (31). During the process, temperature hadtwo effects on accumulation of hydrogen peroxide peroxide: a) when temperature is increased, dissolving of oxygen decreased; b) peroxide had a low solubility in higher temperature. When temperature increased to more than $30^{\circ} \mathrm{C}$, dye decomposition declined because of decomposition of hydrogen peroxide. Also the negative effect of temperature on contaminant re- 
moval can be described as low concentration of dissolved oxygen (DO) and spontaneous decomposition of peroxide in high temperatures (20). Usually when temperature increases, hydrogen peroxide concentration decreases, because increasing the temperature reduces DO to wastewater. Devi et al. reported that by increasing temperature from 30 to $50^{\circ} \mathrm{C}$, Alizarin Red decomposed very well (34). Ayodele et al. (19) showed that phenol decomposition increased with varying the temperature from $22^{\circ} \mathrm{C}$ to $27^{\circ} \mathrm{C}$; it also proved that by increasing the temperature, oxidation and mineralization rates improved by decreasing the hydrogen peroxide and Fe(II). This phenomenon can be due to the increasing reaction between hydrogen peroxide and any sort of iron ions that finally lead to generation of hydroxyl radicals or a high capacity of iron species (19).

\subsection{The Effect of $\mathrm{H}_{2} \mathrm{O}_{2}$}

In the Fenton process, hydrogen peroxide plays an essential role in contaminant removal efficiency. Figure 3 shows the effect $\mathrm{H}_{2} \mathrm{O}_{2}$ concentration on reactive dye removal percentage from colored solutions. An increase in $\mathrm{H}_{2} \mathrm{O}_{2}$ concentration from 2 to $5 \mathrm{mM}$ causes an increasing in the dye removal percentage. Improvement in dye removal can be attributed to increase of hydroxyl radicals as a result of growing growth (31). When $\mathrm{H}_{2} \mathrm{O}_{2}$ concentration increases, the reaction time gets shorter. Minimum removal efficiency was observed in higher concentrations of $\mathrm{H}_{2} \mathrm{O}_{2}(>5 \mathrm{mM})$. The slow decomposition of reactive dye at higher concentrations of $\mathrm{H}_{2} \mathrm{O}_{2}$ was due to the conversion of the generated hydroxyl radicals to hydroxyl ions, reaction of hydroxyl radicals, prohibition of its formation and $\mathrm{H}_{2} \mathrm{O}_{2}$ dissociation with oxygen and $\mathrm{H}_{2} \mathrm{O}$ that change precipitate $\mathrm{Fe}^{3+}$ ions. The sequences above are in accordance with the following equations (35):

$$
\text { 12. } \mathrm{H}_{2} \mathrm{O}_{2} \rightarrow \mathrm{HO}^{\bullet}+\mathrm{HO}^{\bullet}
$$$$
\text { 13. } \mathrm{Fe}^{2+}+\mathrm{HO}^{-} \rightarrow \mathrm{Fe}^{3+}+\mathrm{OH}^{-}
$$$$
\text { 14. }\left[\mathrm{Fe}^{3+}\right]\left[\mathrm{OH}^{-}\right] \rightarrow \mathrm{Ksp} \mathrm{Fe}(\mathrm{OH})^{3}
$$

In other words, the deactivation of $\mathrm{Fe}^{2+}$ takes place at higher dosages of $\mathrm{H}_{2} \mathrm{O}_{2}$, thus giving a brownish yellow precipitate at higher dosages (29). Zhang et al. (28)reported that efficiency of hydrogen peroxide for removing organic materials in the leachate decreased with the increase of Fenton's reagent dosage. At a high dosage of $\mathrm{H}_{2} \mathrm{O}_{2}$, the decrease in removal efficiency was due to the hydroxyl radical scavenging effect of $\mathrm{H}_{2} \mathrm{O}_{2}$ (Equations 15 and 16) and the recombination of the hydroxyl radical (Equation 17) (10):

$$
\begin{aligned}
& \text { 15. } \mathrm{HO}^{\bullet}+\mathrm{H}_{2} \mathrm{O}_{2} \rightarrow \mathrm{HO}_{2} \bullet+\mathrm{H}_{2} \mathrm{O} \\
& \text { 16. } \mathrm{HO}_{2}^{\bullet}+\mathrm{HO}^{\bullet} \rightarrow \mathrm{H}_{2} \mathrm{O}+\mathrm{O}_{2} \\
& \text { 17. } 2 \mathrm{HO}^{\bullet} \rightarrow \mathrm{H}_{2} \mathrm{O}_{2}
\end{aligned}
$$

According to the literature, stepwise $\mathrm{H}_{2} \mathrm{O}_{2}$ addition could be more effective than applying a large initial dose. This could be due to scavenging of $\mathrm{OH}^{\bullet}$ by $\mathrm{H}_{2} \mathrm{O}_{2}$, according to reaction 18 (36):

$$
\text { 18. } \mathrm{OH}^{\bullet}+\mathrm{H}_{2} \mathrm{O}_{2} \rightarrow \mathrm{HO}_{2}^{\bullet}+\mathrm{H}_{2} \mathrm{O}
$$

Reaction 18 contends better with reaction seven at higher concentrations of $\mathrm{H}_{2} \mathrm{O}_{2}$, reducing the oxidation rate of the target dye compound. Hydroxyl radical concentration increased when the $\mathrm{H}_{2} \mathrm{O}_{2} / \mathrm{Fe}^{2+}$ ratio increased that led to greater oxidation of dye. In this study, $\mathrm{H}_{2} \mathrm{O}_{2}$ dosage in the Fenton and modified Fenton processes were chosen as 11 and $5 \mathrm{mM}$ as the optimum dosage, respectively.

\subsection{The Effect of Iron Concentration}

There are no hydroxyl radicals devoid of ions, so the iron ion concentration is essential because increasing the hydroxyl radicals and the coagulation phenomenon lead to a decrease of contaminants. Fenton efficiency can be enhanced by increasing the Fe(II) and Fe(III) concentration, since hydroxyl radical concentration [the same key oxidant] was increased by increasing the Fe(II) concentration. Hydrogen peroxide is not strong enough to oxidize big molecules such as pigments in wastewater dye without the presence of Fe(III) (37). By adding a quantity of Fe(III), removal efficiency will increase. Wang et al. reported that $\mathrm{Fe}(\mathrm{II})$ ions reduce COD amount by increasing $\mathrm{Fe}$ (II) (0.33 mM), where COD removal efficiency reached $43 \%$ from $19 \%$ (38). Zhou et al. found that methylene red removal was increased from $45 \%$ to $75 \%$ in presence of $\mathrm{Fe}(\mathrm{II})$ at 10 minutes (39). The effect of ferric and ferrous dosage on removal efficiency is shown in Figures 3 and 4; the plots illustrate that an increase in iron ion concentration, results in a decrease in the percentage of dye removal. The use of high concentrations of $\mathrm{Fe}^{2+}$ (for a given hydrogen peroxide concentration) accelerated the rate of decomposition of the hydrogenperoxide generated perhydroxyl radicals $\left[\mathrm{HO}_{2}{ }^{\circ}\right]$ which is considered to be the rate limiting step, while lower doses of $\mathrm{Fe}^{2+}$ favored the reaction to generate $\mathrm{OH}^{\bullet}$ which is mor ereactive than $\mathrm{HO}_{2} \cdot$ radicals. Beyond the dosage, $2 \mathrm{mM}$ inactivation of the $\mathrm{Fe}^{2+}$ occurred owing to instantaneous formation of hydroxyl ion in accordance with the following reaction (33):

$$
\text { 19. } \mathrm{OH}^{\bullet}+\mathrm{Fe}^{2+} \rightarrow \mathrm{OH}^{-}+\mathrm{Fe}^{3+}
$$

This takes place at a faster rate than the formation of hydroxyl radical from $\mathrm{Fe}^{2+}$ and peroxide. In conclusion, more reduction in dye removal was observed as more catalyst was added earl in the reaction. The Fenton reaction occurred during the first 10 - 40 minutes. Then, the rate of Fenton reaction due to production of $\mathrm{Fe}^{+2}$ by $\mathrm{Fe}^{+3}$ became slower and decolorization stopped (37). By increasing the iron ions above these values, removal efficiency did not increased because of the tendency of the hydroxyl radicals to react with $\mathrm{Fe}^{2+}$ and $\mathrm{H}_{2} \mathrm{O}_{2}$ in the oxidation-reduction reaction (29). In this paper, $\mathrm{Fe}^{2+}$ and $\mathrm{Fe}^{3+}$ dosage of 3 and $1 \mathrm{mM}$ were selected as the optimum dosage respectively.

\subsection{The Effect of Dye Concentration}

Dye concentration is effective on dye removal percentage. Figure 8 shows the effect of various dye concentra- 
tions $(10,50,500 \mathrm{mg} / \mathrm{L})$ on removal efficiency $[\mathrm{pH}=3$, $\mathrm{Fe}(\mathrm{II})$ and $\mathrm{Fe}(\mathrm{III})$ concentration $50 \mathrm{mg} / \mathrm{L}$, contact time of 10 minutes]. The line reveals that an increase in the dye concentration from 10 to $500 \mathrm{mg} / \mathrm{L}$, reduces the percentage of dye removal, because by increasing the concentration and keeping the $\mathrm{H}_{2} \mathrm{O}_{2}$ value stable, the hydroxyl radicals produced also become stable, thereby the removal percentage will reduce $(29,36)$. RR-198 and RB-19 removal percentage was determined in $50 \mathrm{mg} / \mathrm{L}$ of dye. The Present study was performed with the aim of evaluating the Fenton and modified Fenton processes in removal of reactive red 198 and Reactive Blue 19 from aqueous environments. The effect of various operating parameters such as $\mathrm{H}_{2} \mathrm{O}_{2} / \mathrm{Fe}^{2+}, \mathrm{H}_{2} \mathrm{O}_{2} / \mathrm{Fe}^{3+}$, $\mathrm{pH}$, reaction time, temperature and initial concentration of dye was investigated. The results of this study showed that the most effective dye removal agents are $\mathrm{H}_{2} \mathrm{O}_{2} / \mathrm{Fe}^{2+}, \mathrm{H}_{2} \mathrm{O}_{2} / \mathrm{Fe}^{3+}$, equal to $11 / 3$ and $5 / 1 \mathrm{mM}$ at $\mathrm{pH}=3$ respectively. Dye removal efficiency for reactive red 198 and Reactive Blue 19 utilizing the Fenton and modified Fenton processes were 99.43, 99.31, 94.8 and $90.98 \%$, respectively (initial dye concentration 50 $\mathrm{mg} / \mathrm{L}$ and reaction time of 10 minutes). The findings of this study showed that removal efficiency reduced with increase of dye concentration in fixed conditions for other parameters. Finally, it can be concluded that the modified Fenton process is superior to the Fenton process for dye removal from aqueous solutions.

\section{Acknowledgements}

We would like to thank the laboratory experts for their assistance.

\section{Authors' Contribution}

The overall implementation of this study including design, experiments and data analysis, and manuscript preparation which were the results of joint efforts by individuals who are listed as co-authors of this paper. All authors have made extensive contribution in the review and finalization of this manuscript.

\section{Financial Disclosure}

There were no conflicts of interests.

\section{Funding/Support}

This research was funded by Zahedan University of Medical Sciences (grant No. 91.254).

\section{References}

1. Bansal P, Sud D. Photodegradation of commercial dye, CI Reactive Blue 160 using ZnO nanopowder: Degradation pathway and identification of intermediates by GC/MS. Sep Purif Tech. 2012;85:112-9.

2. Champagne PP, Nesheim ME, Ramsay JA. Effect of a non-ionic surfactant, Merpol, on dye decolorization of Reactive blue 19 by laccase. Enzyme Microb Technol. 2010;46(2):147-52.

3. Dutta S, Parsons SA, Bhattacharjee C, Jarvis P, Datta S, Bandyopad- hyay S. Kinetic study of adsorption and photo-decolorization of Reactive Red 198 on TiO2 surface. Chem Engin J. 2009;155(3):674-9.

4. Gemeay AH, El-Ghrabawy GR, Zaki AB. Kinetics of the oxidative decolorization of Reactive Blue-19 by acidic bromate in homogeneous and heterogeneous media. Dyes Pigments. 2007;73(1):90-7.

5. He Z, Lin L, Song S, Xia M, Xu L, Ying H, et al. Mineralization of C.I. Reactive Blue 19 by ozonation combined with sonolysis: Performance optimization and degradation mechanism. Sep PurifTech. 2008;62(2):376-81.

6. Tunali Akar S, Gorgulu A, Akar T, Celik S. Decolorization of Reactive Blue 49 contaminated solutions by Capsicum annuum seeds: Batch and continuous mode biosorption applications. Chem Engin J. 2011;168(1):125-33.

7. Siddique M, Farooq R, Khalid A, Farooq A, Mahmood Q, Farooq U, et al. Thermal-pressure-mediated hydrolysis of Reactive Blue 19 dye. J Hazard Mater. 2009;172(2-3):1007-12.

8. Feng F, Xu Z, Li X, You W, Zhen Y. Advanced treatment of dyeing wastewater towards reuse by the combined Fenton oxidation and membrane bioreactor process. J Environ Sci (China). 2010;22(11):1657-65.

9. Ozcan A, Omeroglu C, Erdogan Y, Ozcan AS. Modification of bentonite with a cationic surfactant: An adsorption study of textile dye Reactive Blue 19. J Hazard Mater. 2007;140(1-2):173-9.

10. Nidheesh PV, Gandhimathi R. Trends in electro-Fenton process for water and wastewater treatment: An overview. Desalination. 2012;299:1-5.

11. Gulnaz O, Sahmurova A, Kama S. Removal of Reactive Red 198 from aqueous solution by Potamogeton crispus. Chem Engin J. 2011;174(2-3):579-85.

12. Kaur S, Singh V. TiO2 mediated photocatalytic degradation studies of Reactive Red 198 by UV irradiation. J Hazard Mater. 2007;141(1):230-6.

13. Moussavi G, Mahmoudi M. Degradation and biodegradability improvement of the reactive red 198 azo dye using catalytic ozonation with MgO nanocrystals. Chem Engin J. 2009;152(1):1-7.

14. Fanchiang JM, Tseng DH. Degradation of anthraquinone dye C.I Reactive Blue 19 in aqueous solution by ozonation. Chemosphere. 2009;77(2):214-21.

15. Madrakian T, Afkhami A, Ahmadi M. Simple in situ functionaliz ing magnetite nanoparticles by reactive blue-19 and their application to the effective removal of $\mathrm{Pb} 2+$ ions from water samples. Chemosphere. 2013;90(2):542-7.

16. Song S, Yao J, He Z, Qiu J, Chen J. Effect of operational parameters on the decolorization of C.I. Reactive Blue 19 in aqueous solution by ozone-enhanced electrocoagulation. J Hazard Mater 2008;152(1):204-10.

17. da Silva ME, Firmino PI, dos Santos AB. Impact of the redox mediator sodium anthraquinone-2,6-disulphonate (AQDS) on the reductive decolourisation of the azo dye Reactive Red 2 (RR2) in one- and two-stage anaerobic systems. Bioresour Technol. 2012;121:1-7.

18. Shah PD, Dave SR, Rao MS. Enzymatic degradation of textile dye Reactive Orange 13 by newly isolated bacterial strain Alcaligenes faecalis PMS-1. Int Biodeterior Biodegradation. 2012;69:41-50.

19. Ayodele OB, Lim JK, Hameed BH. Degradation of phenol in photoFenton process by phosphoric acid modified kaolin supported ferric-oxalate catalyst: Optimization and kinetic modeling. Chem Engin J. 2012;197:181-92.

20. Bianco B, De Michelis I, Veglio F. Fenton treatment of complex industrial wastewater: optimization of process conditions by surface response method. J Hazard Mater. 2011;186(2-3):1733-8.

21. Blanco J, Torrades F, De la Varga M, García-Montaño J. Fenton and biological-Fenton coupled processes for textile wastewater treatment and reuse. Desalination. 2012;286:394-9.

22. Popuri SR, Chang CY, Xu J.A study on different addition approach of Fenton's reagent for DCOD removal from ABS wastewater. Desalination. 2011;277(1):141-6.

23. Ramirez JH, Duarte FM, Martins FG, Costa CA, Madeira LM. Modelling of the synthetic dye Orange II degradation using Fenton's reagent: From batch to continuous reactor operation. Chem Engin J. 2009;148(2-3):394-404.

24. Shi J, Lu C, Yan D, Ma L. High selectivity sensing of cobalt in 


\section{Jafari Mansoorian Het al.}

HepG2 cells based on necklace model microenvironment-modulated carbon dot-improved chemiluminescence in Fenton-like system. Biosens Bioelectron. 2013;45:58-64.

25. Zorpas AA, Costa CN. Combination of Fenton oxidation and composting for the treatment of the olive solid residue and the olive mile wastewater from the olive oil industry in Cyprus. Bioresour Technol. 2010;101(20):7984-7.

26. Zhuang L, Zhou S, Yuan Y, Liu M, Wang Y. A novel bioelectro-Fenton system for coupling anodic COD removal with cathodic dye degradation. Chem Engin J. 2010;163(1-2):160-3.

27. Turan-Ertas T, Gurol MD. Oxidation of diethylene glycol with ozone and modified Fenton processes. Chemosphere. 2002;47(3):293-301.

28. Zhang H, Choi HJ, Huang CP. Optimization of Fenton process for the treatment of landfill leachate. J Hazard Mater. 2005;125(13):166-74.

29. Karthikeyan S, Titus A, Gnanamani A, Mandal AB, Sekaran G. Treatment of textile wastewater by homogeneous and heterogeneous Fenton oxidation processes. Desalination. 2011;281:438-45.

30. Yang Y, Wang P, Shi S, Liu Y. Microwave enhanced Fenton-like process for the treatment of high concentration pharmaceutical wastewater. J Hazard Mater. 2009;168(1):238-45.

31. Wu H, Wang S. Impacts of operating parameters on oxidation-reduction potential and pretreatment efficacy in the pretreatment of printing and dyeing wastewater by Fenton process. J Hazard Mater. 2012;243:86-94.

32. Goi A, Veressinina Y, Trapido M. Degradation of salicylic acid by Fenton and modified Fenton treatment. Chem Engin J. 2008;143(1-3):1-9.

33. Weng CH, Lin YT, Chang CK, Liu N. Decolourization of direct blue 15 by Fenton/ultrasonic process using a zero-valent iron aggregate catalyst. Ultrason Sonochem. 2013;20(3):970-7.

34. Devi LG, Munikrishnappa C, Nagaraj B, Rajashekhar KE. Effect of chloride and sulfate ions on the advanced photo Fenton and modified photo Fenton degradation process of Alizarin Red S. $J$ Mol Catal A Chem. 2013;374-375:125-31.

35. Wei J, Song Y, Tu X, Zhao L, Zhi E. Pretreatment of dry-spun acrylic fiber manufacturing wastewater by Fenton process: Optimization, kinetics and mechanisms. Chem Engin J. 2013;218:319-26.

36. Huang YH, Huang YF, Chang PS, Chen CY. Comparative study of oxidation of dye-Reactive Black B by different advanced oxidation processes: Fenton, electro-Fenton and photo-Fenton. $J$ Hazard Mater. 2008;154(1-3):655-62.

37. Hodaifa G, Ochando-Pulido JM, Rodriguez-Vives S, MartinezFerez A. Optimization of continuous reactor at pilot scale for olive-oil mill wastewater treatment by Fenton-like process. Chem Engin J. 2013;220:117-24.

38. Wang CT, Chou WL, Chung MH, Kuo YM. COD removal from real dyeing wastewater by electro-Fenton technology using an activated carbon fiber cathode. Desalination. 2010;253(1-3):129-34.

39. Zhou M, Yu Q, Lei L, Barton G. Electro-Fenton method for the removal of methyl red in an efficient electrochemical system. Sep PurifTech. 2007;57(2):380-7. 